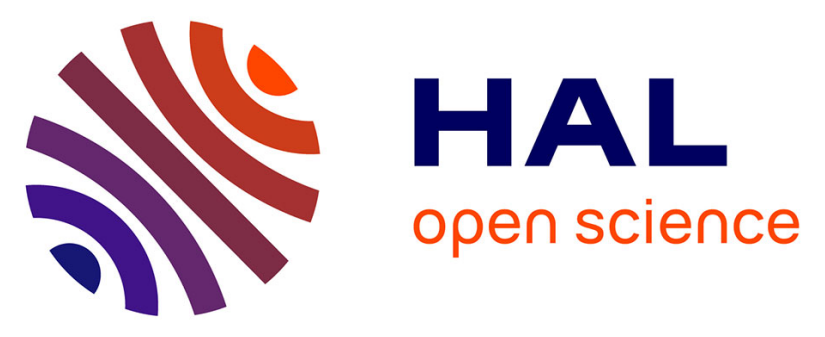

\title{
Temporal Modeling of Invasive Species' Migration in Greece from Neighboring Countries Using Fuzzy Cognitive Maps
}

Konstantinos Demertzis, Vardis-Dimitris Anezakis, Lazaros Iliadis, Stefanos Spartalis

\section{To cite this version:}

Konstantinos Demertzis, Vardis-Dimitris Anezakis, Lazaros Iliadis, Stefanos Spartalis. Temporal Modeling of Invasive Species' Migration in Greece from Neighboring Countries Using Fuzzy Cognitive Maps. 14th IFIP International Conference on Artificial Intelligence Applications and Innovations (AIAI), May 2018, Rhodes, Greece. pp.592-605, 10.1007/978-3-319-92007-8_50 . hal-01821047

\section{HAL Id: hal-01821047 \\ https://hal.inria.fr/hal-01821047}

Submitted on 22 Jun 2018

HAL is a multi-disciplinary open access archive for the deposit and dissemination of scientific research documents, whether they are published or not. The documents may come from teaching and research institutions in France or abroad, or from public or private research centers.
L'archive ouverte pluridisciplinaire HAL, est destinée au dépôt et à la diffusion de documents scientifiques de niveau recherche, publiés ou non, émanant des établissements d'enseignement et de recherche français ou étrangers, des laboratoires publics ou privés.

\section{(c)(1)}

Distributed under a Creative Commons Attribution| 4.0 International License 


\title{
Temporal Modeling of invasive species' migration in Greece from neighboring countries using Fuzzy Cognitive Maps
}

\author{
Konstantinos Demertzis ${ }^{1}$, Vardis-Dimitris Anezakis ${ }^{2}$, Lazaros Iliadis ${ }^{3^{*}}$ and \\ Stefanos Spartalis ${ }^{4}$ \\ 1, 3* Democritus University of Thrace, School of Engineering, Department of Civil Engineering, \\ University Campus, Kimmeria, 67100, Xanthi, Greece \\ ${ }^{2}$ Democritus University of Thrace, Lab of Forest-Environmental Informatics and \\ Computational Intelligence, 193 Pandazidou st., 68200 N Orestiada, Greece \\ ${ }^{4}$ Lab of Computational Mathematics, School of Engineering, Department of Production and \\ Management Engineering, Democritus University of Thrace, V.Sofias 12, Prokat, Building A1, \\ 67100 Xanthi, Greece \\ kdemertz@fmenr.duth.gr ${ }^{1}$, danezaki@fmenr.duth.gr ${ }^{2}$, liliadis@ civil.duth.gr ${ }^{3}$, \\ $\underline{\text { sspart@pme.duth.gr }}{ }^{4}$
}

\begin{abstract}
A serious side effect of climate change is the spread of invasive species (INSP), which constitute a serious and rapidly worsening threat to ecology, to the preservation of natural biodiversity, to the protection of flora and fauna and it can even threaten human population health. These species do not seem to have particular morphological differences, despite the intense variations in their biological characteristics. This often makes their identification very difficult. The need to protect the environment and to safeguard public health requires the development of sophisticated methods for early and valid identification which can lead to timely rational management measures. The aim of this research is the development of an advanced Computational Intelligence (COIN) system, capable to effectively analyze the conditions that influence and favors spreading of invasive species, due to the problem of climate change. Fuzzy Cognitive Maps (FCM) have been used to determine the specific temporal period (in years) in which the rapidly changing average temperature and precipitation in Greece, will become identical to the respective values of the neighboring countries for the period 1996-2015. This climatic evolution will cause spread of INSP met in these Mediterranean countries, to Greece. Separate analysis has been done for several cases of invasive species. The whole analysis is based on climate change models up to 2100 .
\end{abstract}

Keywords: Fuzzy Cognitive Maps, Invasive Species, Species Distribution Model, Soft Computing Techniques, Bioclimatic Data, Climate Change Scenarios, Greece

\section{Introduction}

\subsection{Invasive species}

The potential impacts of climate change are evident at various levels of biological organization and particularly in the disturbances of biodiversity, in the biodegradability of organisms and the emergence of invasive species [15]. The Invasive species are entering new foreign habitats and they can stifle natural flora or 
fauna and harm the environment. They can even have negative social and economic impact on human health, agriculture, fisheries and food production. The usual reason for the movement of these species is search of colder climates, either because their natural environment does not meet the range of temperatures they can survive, or because they follow different species of plants or organisms that migrate to colder ecosystems. Although not all alien species are harmful, it is imperative to draw up a management plan according to their degree of risk. Control or eradication of these species and restoration of the ecosystems affected by them is necessary. Timely identification of INSP can slow down the uncontrolled expansion of the problem and it can increase the likelihood of eliminating the phenomenon before it is widely established and ultimately avoid the need for costly and long-term control efforts.

\subsection{Related Literature - Innovations of the Proposed Methodology}

There are some studies in the literature using statistical approaches and only a few employing Soft Computing Techniques to model the spread of invasive species in other countries. However, none of them aims in INSP expansion projection into the future, by estimating specific time intervals using fuzzy cognitive maps.

Coro et al., [5] constructed and produced an overall habitat suitability map and an effective geographical spread map for L. sceleratus at Mediterranean scale by using cloud computing-based algorithms to merge seven machine learning approaches. The results suggest that without an intervention, L. sceleratus will continue its rapid spread and will likely have a high impact on fisheries. Paini et al., [12] using global presence/absence data of insect crop pests employed a self-organizing map (SOM) to categorize regions based on similarities in species assemblages. This technique enabled them to generate a list of species and rank them based on an index of the risk of establishment. Gevrey and Worner, [6] predicted the worldwide distribution of two pest species based on climatic factors. They used an artificial neural network, the multilayer perceptron, trained using the backpropagation algorithm, to model the distribution of each species. Capinha et al., [4] calculated consensus predictions for current conditions and 3 future time periods (2030, 2050 and 2080) under low and high scenarios of greenhouse gas emissions, from an ensemble of forecasts generated by 5 distinct algorithms (generalized linear models, artificial neural networks, support vector machines, random forests and alternating decision trees). Sadeghi et al., [16] used support vector machines (SVMs) methods in order to predict distribution pattern of Azolla filiculoides. Various structural habitat and physico-chemical variables were used as inputs and 3 classes (low, medium and high) of cover percentage of Azolla were served as output for the models. Gras et al., [7] presented an individual-based predator-prey model in which each agent behavior is modeled by a fuzzy cognitive map and allows its evolution through the epochs of the simulation. Ramsey and Norbury, [14] used a method to assist decision making using FCM. Their approach took into account interactions between pests and conservation assets in complex food webs. Also, there are some research efforts on the expansion and distribution of INSP due to climate change $[8-10,13,20]$ but none of them for the neighboring area of Greece. 
This paper proposes an innovative system that performs analysis of the climate features that favor the expansion of five invasive species to Greece from neighboring countries. Also, it proposes a model of medium and long-term forecasting of temporal periods related to the potential future identification of these INSP in Greece, due to severe changes in the country's climate til 2100. Initially, the countries in which the five INSP have been listed and their climatic conditions for the period 1996-2015 have being explored. Correlation Analysis of 12 parameters for the above time-period has been performed by using values recorded in Greece. Finding the values of the positive and negative correlations and their fuzzy Linguistics, contributes to their comprehensive representation in the modeling process of the FCM. The fuzzy values of the positive and negative correlations are introduced as weights into the FCM, thereby specifying the degree of interaction of a parameter's change to the other interconnected parameters. The future climatic AVTE and AVPRE of Greece, have been formulated on the basis of the projections of a variety of climatic models and scenarios of the latest project CMIP5 (Coupled Model Inter-comparison Project Phase5) for the period up to 2100.

\subsection{Description of data}

Correlation analysis of twelve bioclimatic parameters with values from Greece was performed for the period 1996-2015 [13], in order to make a symbolic representation of the complex associations of the climatic conditions with the FCM approach. Totally, five (5) INSP were studied in this research. The four of them are included in the 100 most dangerous species of the planet and they are: Trogoderma granarium (Insect) the Acacia mearnsii (Shrub) the Trachemys scripta elegans (Reptile) and the Acridotheres tristis (Bird) [11]. The fifth is known as Eupatorium cannabinum (Herb) and it is the most frequently recorded in 10 neighboring countries (NECO). The average temperature (AVTE) and precipitation (AVPRE) values of the 11 NECO (where the above INSP were identified) were taken into consideration.

The estimation of the future AVTEM and AVPRE values in Greece for the period 2020-2099 was based on the consideration of sixteen timely and reliable climate models of the project CMIP5.

\section{Theoretical Frameworks and Methodology}

\subsection{Correlation Analysis}

The relativity analysis with the Pearson(r) parametric correlation coefficient method was used to test the existence of a linear relationship between the parameters. The Pearson linear correlation coefficient of two variables $X$ and $Y$ is defined based on a sample of n pairs of observations $\left(x_{i}, y_{i}\right) i=1,2, \ldots, n$, and it is denoted as $r(X, Y)$ or simply as $r$.

The variables $\bar{x}$ and $\bar{y}$ are the averages of (xi, yi). The $r$ is the covariance (Cov X, $\mathrm{Y})$ of the two variables divided by the product of their standard deviations ( $x$, sy). It is given by the following equation 1 : 


$$
r=\frac{s_{x y}}{s_{x} s_{y}}=\frac{\sum_{i=1}^{v}\left(x_{i}-\bar{x}\right)\left(y_{i}-\bar{y}\right)}{\sqrt{\sum_{i=1}^{v}\left(x_{i}-\bar{x}\right)^{2}} \sqrt{\sum_{i=1}^{v}\left(y_{i}-\bar{y}\right)^{2}}}=\frac{\sum_{i=1}^{\mathrm{v}} x_{i} y_{i}-v \bar{x} \bar{y}}{\sqrt{\sum_{i=1}^{\mathrm{v}} x_{i}^{2}-v \bar{x}^{2}} \sqrt{\sum_{i=1}^{\mathrm{v}} y_{i}^{2}-v \bar{y}^{2}}}
$$

The correlation coefficient is a pure number in the closed interval $-1 \leq r \leq 1$. More specifically, when $0<r \leq 1$, then $X, Y$ are positively linearly correlated. When $-1<r<0$, then $X, Y$ are negatively linearly correlated. When $r=0$, there is no correlation at all [3].

\subsection{Fuzzy Cognitive Maps}

In the fuzzy cognitive map models, the nodes are interconnected with edges and each edge connecting two nodes, describes the variation of the state activation value of the one node, in the configuration of the state activation value of the interconnected node. The direction of the edge implies which node affects which, where the sign of the causality relationship is positive, if there is a direct relationship of influence, negative if there is an inverse relation of influence and zero if the two nodes are uncorrelated. Relations of causality usually defined by specialists are described using fuzzy linguistic variables, and they are fuzzified by using membership functions in the interval $[-1,1][17,19]$.

Unlike the majority of complex dynamic systems characterized by non-linearity and great uncertainty, FCM utilize advanced learning techniques to select appropriate weights for causal interrelationships between the variables examined.

This feature helps them to capture the problem in question with absolute realism. FCM cover the need of comparing and characterizing reference sets, solving and modeling complex problems for which there is no exact mathematical model. This is achieved by employing the theoretical background of fuzzy logic. FCM are an efficient tool in modeling multiparametric problems which call for long term decisions $[1,2]$.

\subsection{Climate change scenarios employed}

Our research team has already modeled complex systems concerning climate change and its direct impact which is the increased concentration of atmospheric pollutants [1,2]. The Intergovernmental International Panel on Climate Change (IPCC) has published five reports to date. The objective of the program (CMIP5) set in the Fifth Assessment Report on Climate Change (IPCC-AR5, Assessment Report 5) was the planning of climate simulations, which aim at assessing future climate changes in both the short and the long term.

The goal is achieved using Earth System Models (ESM) and global AtmosphericOcean General Circulation Models (AOGCMs). In the last report (AR5) significant improvement was found in temperature and precipitation modeling mechanisms, in the study of anthropogenic effects on the environment and in the study of biochemical cycles. According to this report, four future scenarios of Green House Gases (GHGs) concentrations in the atmosphere have been developed, which are known as the Representative Concentration Pathways (RCPs). 
According to the RCP2.6 scenario, a small increase in greenhouse gas emissions by the middle of the decade, would result in radiation increase to $3 \mathrm{~W} / \mathrm{m}^{2}$ by 2050 , followed by a decrease to $2.6 \mathrm{~W} / \mathrm{m}^{2}$ by the year 2100 . Based on the RCP4.5 and RCP6.0 scenarios, moderate increases in greenhouse gas emissions, would result in a standard increase of the radiation values. Based on the RCP4.5, the radiation values will be stabilized at about $4.5 \mathrm{~W} / \mathrm{m}^{2}$ before 2100 , while based on the RCP6.0 they will be stabilized at $6.0 \mathrm{~W} / \mathrm{m}^{2}$ after 2100 . Finally, according to the most extreme scenario (RCP8.5) which includes a rapid and continuous increase in greenhouse gas concentrations, the radiation will increase above $8.5 \mathrm{~W} / \mathrm{m}^{2}$ and it will continue to have an increasing trend for a certain period after 2100. The following climate models $b c c \_c s m 1 \_1, \quad b c c$ c csm1_1_m, ccsm4, cesm1_cam5, csiro_mk3_6_0, fio_esm, gfdl_cm $3, \quad g f d l \_e s m 2 m, \quad g i s s_{-} e 2 \_h, \quad g i s s_{-} e 2 \_r, \quad i p s l \_c m 5 a \_m r$, miroc_esm, miroc_esm_chem, miroc5, mri_cgcm3, noresm1_m included in the project CMIP5, were employed in this research as the most timely and reliable ones for the estimation of temperature and precipitation future fluctuations for the period 2020-2099 [18].

\section{Description of the proposed methodology}

The basic methodology aims in modeling the occurrence of invasive species in Greece and moreover in predicting the time-period required for the Greek average temperature and precipitation values to become equal to the ones of the neighboring countries. It includes 4 distinct algorithmic stages (Modeling, Grid, Scenarios and Forecasting).

In the first step (modeling) all associated parameters are added and named. They are interconnected with synapses in order to develop the causative negative or positive correlations.

The Fuzzification of the obtained correlations is related to the description of any interconnections between features, with Linguistic terms. This has been implemented by selecting the following six terms: Low Positive (denoted in the FCM as +), Moderate Positive (++), High Positive (+++)), Negative (denoted as -), Moderate Negative (--), High Negative (--)). These linguistics, represent the Fuzzy weights (see Table 1).

Table 1. Linguistics describing the effect and their corresponding fuzzy weight value

\begin{tabular}{cc}
\hline Effect & Value \\
\hline High Positive (+++) & 1 \\
Moderate Positive (++) & 0.5 \\
Low Positive (+) & 0.25 \\
Low Negative (-) & -0.25 \\
Moderate Negative (--) & -0.5 \\
High Negative (---) & -1 \\
\hline
\end{tabular}




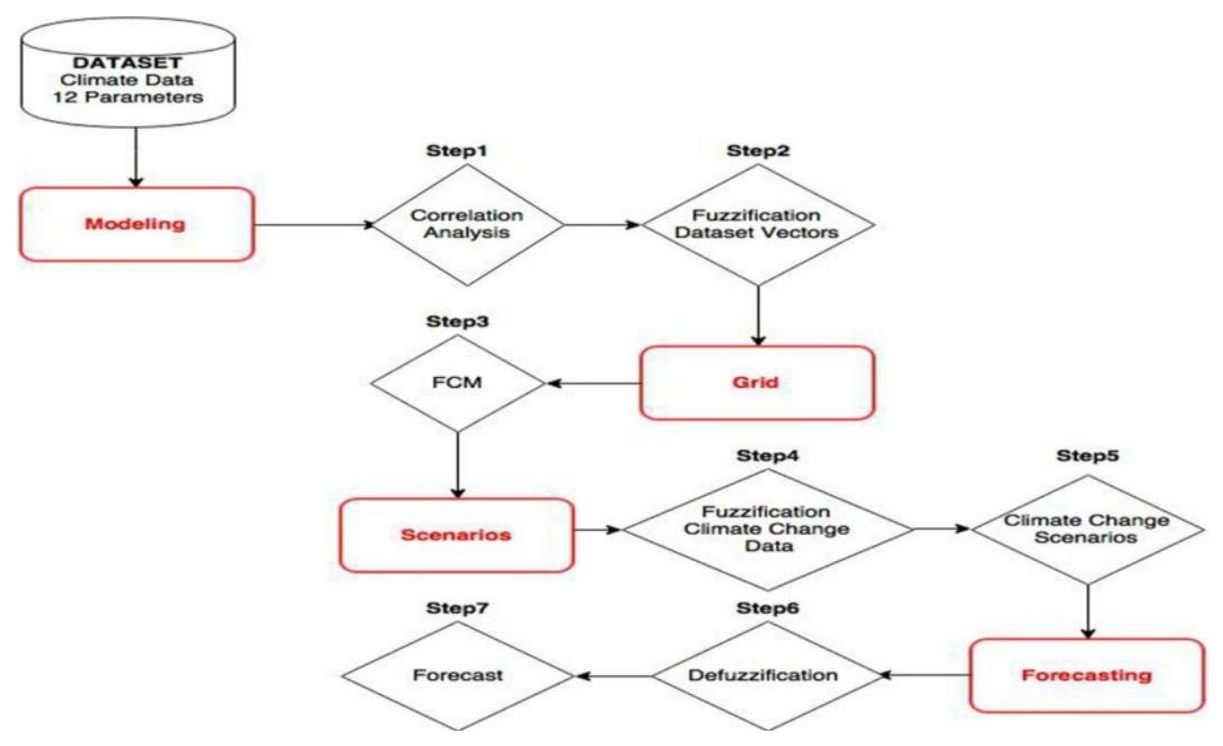

Fig 1. Flowchart of the proposed model

The description of the algorithmic steps is done in the next paragraph:

Step 1 (Modeling): Application of Correlation Analysis for the calculation of the degree of correlation between the variables under consideration (for Greece): absolute air humidity (aah), air temperature (airtemp), frost days frequency (fd), potential evapotranspiration (pet), relative humidity (rh), soil moisture $(\mathrm{sm})$, sunshine fraction (sf), water vapor pressure (wvp), Water vapor saturation pressure (wvsp), wet days frequency (wd), wind speed (ws) and Precipitation (P).

Step 2: Classification of the negative and positive correlations between the parameters used, by fuzzifying their crisp numerical values. This is achieved by employing three Triangular Fuzzy Membership functions (TRIMF equation 2) to classify the types of correlations into the following fuzzy sets "Low Correlation" Moderate Correlation" and "High Correlation". The following equation 2 corresponds to a triangular fuzzy membership function (FMF) where a, b, c are the boundary values defined by the developer.

$$
f(x ; a, b, c)=\max \{\min [(x-a) /(b-a),(c-x) /(c-b)], 0\}
$$

The following table 2 includes the Fuzzy Classification of the correlations among the features of interest.

Step 3 (Grid): This step simulates the interactions between the FCM nodes. This is done by employing an iterative process, which calculates the updated value of each node. This value depends on the ones of the starting edges that point to it, and on the weight assigned to the acne that joins them. Transfer functions are used to transform the result of the sum of the Products of node activation values. A new node value is calculated and the corresponding weight of the connecting edge is estimated and assigned. This is practically the case that transfers the actual value of each variable in 
the closed interval $[-1,1]$. The negative type of influence is shown in orange and the positive in blue. The degree of influence depends on the thickness of each line. The greater the effect, the thicker the line is, as shown in Fig. 2 (Table 3). The parameters used in the correlation analysis and in the development of the fuzzy cognitive map, are related to Greek data vectors for the period 1996-2015. The degree of influence between involved variables is depicted in Fig 2. Mental Modeler provides some details regarding to the architecture of the grid. The number of ordinary concepts (nodes) is 12 and the connections per component are 11. So, the number of total connections between the concepts is $11 * 12=132$.

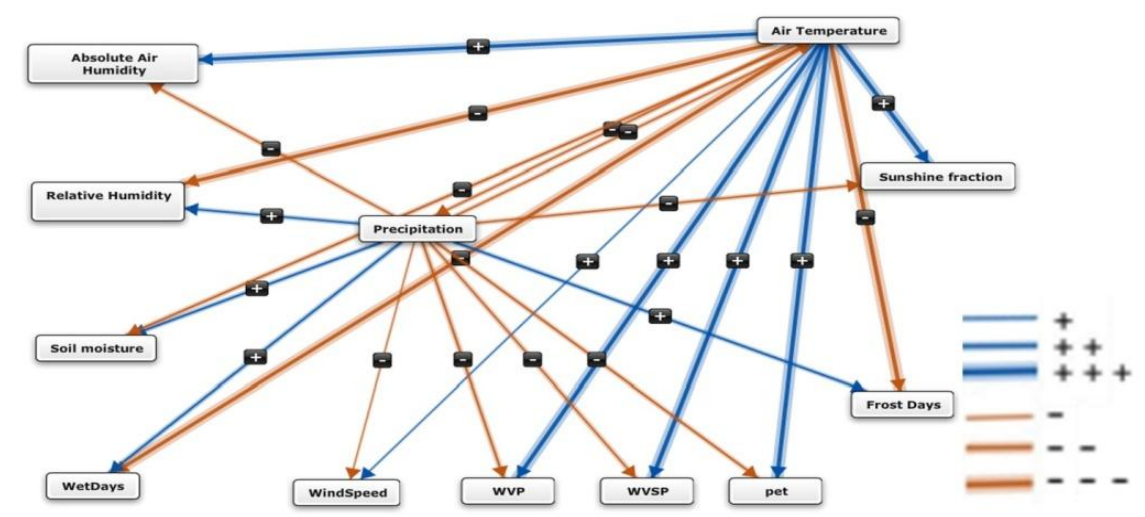

Fig 2. The developed FCM connecting air temperature and precipitation with other variables

Temperature and precipitation changes due to climate change for the period 2020 to 2099 have been fuzzified and proper linguistics have been developed. The whole process was based on sixteen climatic models as well as on extensive testing of a variety of climate scenarios for Greece (RCP2.6, RCP4.5, RCP6.0, RCP8.5). At this stage the mean average temperature value and the mean average precipitation for Greece (1996-2015) were estimated to be $15.66^{\circ} \mathrm{C}$ and $45.81 \mathrm{~mm}$ respectively.

Table 2. Fuzzification of the correlation with corresponding Linguistics

\begin{tabular}{|c|c|c|c|c|c|c|c|c|c|c|c|c|}
\hline & $\mathrm{aah}$ & airtemp & $\mathrm{fd}$ & pet & $\mathrm{P}$ & $\mathrm{rh}$ & $\mathrm{sm}$ & sf & wd & ws & wvp & wvsp \\
\hline aah & 1 & +++ & --- & +++ & -- & --- & -- & +++ & --- & - & +++ & +++ \\
\hline airtemp & +++ & 1 & --- & +++ & -- & --- & -- & +++ & --- & + & +++ & +++ \\
\hline $\mathrm{fd}$ & --- & --- & 1 & --- & ++ & +++ & ++ & --- & ++ & + & --- & --- \\
\hline pet & +++ & +++ & --- & 1 & -- & --- & -- & +++ & --- & + & +++ & +++ \\
\hline $\mathrm{P}$ & -- & -- & ++ & -- & 1 & ++ & ++ & -- & ++ & - & -- & -- \\
\hline rh & --- & --- & +++ & --- & ++ & 1 & ++ & --- & +++ & -- & --- & --- \\
\hline $\mathrm{sm}$ & -- & -- & ++ & -- & ++ & ++ & 1 & -- & ++ & ++ & -- & -- \\
\hline sf & +++ & +++ & --- & +++ & -- & --- & -- & 1 & --- & + & +++ & +++ \\
\hline wd & --- & --- & ++ & --- & ++ & +++ & ++ & --- & 1 & - & --- & --- \\
\hline ws & - & + & + & + & - & -- & ++ & + & - & 1 & - & + \\
\hline wvp & +++ & +++ & --- & +++ & -- & --- & -- & +++ & --- & - & 1 & +++ \\
\hline
\end{tabular}




\begin{tabular}{lllllllllllllll}
\hline wVsp & +++ & +++ & --- & +++ & -- & --- & -- & +++ & --- & + & +++ & 1 \\
\hline
\end{tabular}

Table 3. Degree of influence of the average Temperature (airtemp) and average Precipitation to the other climatic variables

\begin{tabular}{lcccccccccccc}
\hline & aah & airtemp & fd & pet & P & rh & sm & sf & wd & ws & wvp & wvsp \\
\hline airtemp & +++ & 1 & --- & +++ & -- & --- & -- & +++ & --- & + & +++ & +++ \\
P & -- & -- & ++ & -- & 1 & ++ & ++ & -- & ++ & - & -- & -- \\
\hline
\end{tabular}

Step 4 (Scenarios): Step 4 performs classification of the parameters based on the future changes of the average temperature and precipitation of Greece, as they were estimated by the sixteen climate models. Four overlapping TRIMF and eight SemiTRIMF were employed to fuzzify the crisp values of the parameters involved.

Regarding the period 2020-2099 two TRIMF and four Semi-TRIMF were applied on the crisp values of the average monthly temperature (AVTE) values that ranged in the closed interval $\left[-0.98^{\circ},+8.93^{\circ}\right]$. The 1 st Semi-TRIMF, the first TRIMF and the 2nd Semi-TRIMF were applied on the reduction of the AVTE in the interval $\left[-0.98^{\circ}\right.$, $0^{\mathrm{O}}$ ]. These FMF correspond to the following fuzzy Linguistics: Low Negative (-), Moderate Negative (--), and High Negative (---) with the last containing values close to the highest estimated reduction.

The next Semi-TRIMF, the TRIMF and the last Semi_TRIMF were used for the increase of the AVTE. These FMF correspond to the Low Positive (+), Moderate Positive (++), High Positive (+++), with the late being close to the maximum temperature increase. In the same way, two TRIMF and four Semi-TRIMF were developed for the precipitation.

Table 4. TRIMF and Semi-TRIMF boundary values for the Average Monthly Temperature and Precipitation in Greece.

\begin{tabular}{|c|c|c|}
\hline $\begin{array}{c}\text { Fuzzy Sets } \\
\text { corresponding to Average } \\
\text { Monthly Temperature and } \\
\text { Monthly precipitation } \\
\text { changes }\end{array}$ & $\begin{array}{l}\text { TRIMF and Semi- } \\
\text { TRIMF boundaries } \\
\text { (AVTE in C degrees) }\end{array}$ & $\begin{array}{l}\text { TRIMF and Semi- } \\
\text { TRIMF boundaries } \\
\text { (Precipitation mm) }\end{array}$ \\
\hline --- (Semi-TRIMF) & {$[-0.98-0.588]$} & {$\left[\begin{array}{lll}-29.98 & -17.99]\end{array}\right.$} \\
\hline -- (TRIMF) & {$\left[\begin{array}{llll}-0.882 & -0.49 & -0.098\end{array}\right]$} & {$\left[\begin{array}{lll}-26.98 & -14.99 & -2.998\end{array}\right]$} \\
\hline - (Semi-TRIMF) & {$[-0.3920]$} & {$[-11.990]$} \\
\hline$+($ Semi-TRIMF $)$ & {$\left[\begin{array}{ll}0 & 3.572\end{array}\right]$} & {$\left[\begin{array}{ll}0 & 20.91\end{array}\right]$} \\
\hline$++($ TRIMF $)$ & {$\left[\begin{array}{llll}0.893 & 4.465 & 8.037\end{array}\right]$} & {$\left[\begin{array}{llll}5.232 & 26.15 & 47.06\end{array}\right]$} \\
\hline$+++($ Semi-TRIMF $)$ & {$\left[\begin{array}{lll}5.358 & 8.93\end{array}\right]$} & [31.38 52.29$]$ \\
\hline
\end{tabular}

Step 5: It includes extensive testing on various scenarios based on potential changes in average temperature and precipitation and their effect on other parameters.

Step 6 (Forecasting): The fuzzy Linguistics generated by considering the mentioned climate change scenarios are de-fuzzified in order to produce crisp future values related to all interconnected parameters. In this way a future projection 
regarding the appearance of invasive species in Greece (due to climate change) can be achieved.

For the defuzzification the centroid function was used which estimates the center of gravity of the fuzzy set distribution.

$$
x=\frac{\int x \cdot \mu(x) d x}{\int \mu(x) d x}
$$

Step 7: The index of the magnitude of change for the other correlated parameters is calculated based on the amount of relative change of each parameter as it is given in equation 4.

$$
\text { Relative Change }=\frac{\text { FutureValue }- \text { InitialValue }}{\text { InitialValue }}
$$

\section{Results and Discussion}

The following table 5 presents the changes of the average temperature and average precipitation in Greece (for the four future periods A, B, C, D) based on the historical values of the period 1996-2015. Based on climate changes models, there are five countries where the Combination of Average Temperature and Precipitation (CATEP) (for the period 1996-2015) will become identical with the future respective values for Greece (2020-2099) namely: Cyprus, Italy, Lebanon, Portugal and Israel (Tables 5, 6 and 7).

Table 5. The intervals of the average monthly Temperature and Precipitation changes in Greece, for four future temporal periods till 2099

\begin{tabular}{ccc}
\hline $\begin{array}{c}\text { Future } \\
\text { Periods }\end{array}$ & $\begin{array}{c}\text { Boundaries of future average } \\
\text { monthly temperature change } \\
\text { (in Celcium degrees) }\end{array}$ & $\begin{array}{c}\text { Boundaries of future average } \\
\text { monthly precipitation change } \\
(\mathrm{mm})\end{array}$ \\
\hline $1996-2015$ & $15.66^{\circ} \mathrm{C}$ & $45.81 \mathrm{~mm}$ \\
A 2020-2039 & {$[-0.980][0+4.2]$} & {$[-21.950],[0+49.18]$} \\
B 2040-2059 & {$[-0.750][0+5.55]$} & {$[-24.190],[0+52.29]$} \\
C 2060-2079 & {$[-0.70][0+6.84]$} & {$[-27.370],[0+49.26]$} \\
D 2080-2099 & {$[-0.80],[0+8.93]$} & {$[-29.980],[0+48.78]$} \\
\hline
\end{tabular}

Table 6. Average monthly Temperature and Precipitation changes in Greece for the period 2020-2099. It determines the expansion of 5 INSP (recorded in 11 countries)

\begin{tabular}{cccccc}
\hline Countries & $\begin{array}{c}\text { Crisp } \\
\text { Values of } \\
\text { temperature } \\
\text { change } \\
\text { (Greece }\end{array}$ & $\begin{array}{c}\text { Crisp } \\
\text { Values of } \\
\text { precipitation } \\
\text { change } \\
\text { (Greece }\end{array}$ & Countries & $\begin{array}{c}\text { Crisp } \\
\text { Values of } \\
\text { temperature } \\
\text { change } \\
\text { (Greece }\end{array}$ & $\begin{array}{c}\text { Crisp } \\
\text { Values of } \\
\text { Precipitation } \\
\text { change } \\
\text { (Greece }\end{array}$ \\
& & & $2020-2099)$ & $2020-2099)$ \\
\hline Cyprus & $+4.299^{\circ} \mathrm{C}$ & $+15,52 \mathrm{~mm}$ & Spain & $-3.63^{\circ} \mathrm{C}$ & $-8.29 \mathrm{~mm}$ \\
\hline
\end{tabular}




\begin{tabular}{cccccc}
\hline Israel & $+3.91{ }^{\mathrm{O}} \mathrm{C}$ & $-28.09 \mathrm{~mm}$ & Turkey & $-5.36{ }^{\circ} \mathrm{C}$ & $+2.12 \mathrm{~mm}$ \\
Italy & $+0.1{ }^{\mathrm{O}} \mathrm{C}$ & $+41.22 \mathrm{~mm}$ & Albania & $-2.49{ }^{\circ} \mathrm{C}$ & $+18.33 \mathrm{~mm}$ \\
Lebanon & $+3.44{ }^{\mathrm{O}} \mathrm{C}$ & $-15.51 \mathrm{~mm}$ & Bulgaria & $-4.04{ }^{\mathrm{O}} \mathrm{C}$ & $+13.85 \mathrm{~mm}$ \\
Portugal & $-0.23{ }^{\circ} \mathrm{C}$ & $+12.98 \mathrm{~mm}$ & Syria & $+3.15{ }^{\circ} \mathrm{C}$ & $-35.27 \mathrm{~mm}$ \\
& & & Egypt & $+6.73{ }^{\circ} \mathrm{C}$ & $-41.41 \mathrm{~mm}$ \\
\hline
\end{tabular}

The future CATEP intervals for Greece were fuzzified in order to estimate the temporal intervals for the appearance of specific Invasive Species. A variety of scenarios have been examined. Based on them and on the application of two climate models, the species Acacia mearnsii is expected to appear in the country during the period 2020-2039. This could be caused by the combination of a small increase $+0.1^{\mathrm{O}} \mathrm{C}$ in the Average Temperature (AVTE) denoted as (+) with a High increase $(+++)$ of the Average Precipitation (AVPRE) by $+41.22 \mathrm{~mm}$. The combined effect of a small decrease (-) of the AVTE $\left(-0.23^{\circ} \mathrm{C}\right)$ with a small increase $(+)$ of the AVPRE $(+12.98 \mathrm{~mm})$ would have similar result. The future values for these parameters in Greece from 2020 to 2039 will be identical to the corresponding values of Italy and Portugal for the period 1996-2015 (Table 7). The species Acacia mearnsii which appeared in Israel from 1996 to 2015 is expected to appear in Greece during the period 2080-2099, due to the combined Moderate increase $(++)$ of the AVTE $\left(+3.91^{\circ} \mathrm{C}\right)$ and the Moderate decrease of AVPRE (---) $(-28.09 \mathrm{~mm})$ (Table7). For the Acacia mearnsii the combined AVTE and AVPRE values (1996-2015) of the three countries (Italy, Portugal, Israel) will be identical with the corresponding values for Greece for the period 2080-2099.

Table 7. Presentation of: a) Changes in CATEP b) Estimated temporal period for the invasive species appearance in Greece

\begin{tabular}{cccc}
\hline $\begin{array}{c}\text { Species- } \\
\text { Countries } \\
1996-2015\end{array}$ & $\begin{array}{c}\text { Appearance in } \\
\text { Greece }\end{array}$ & $\begin{array}{c}\text { Crisp Values of } \\
\text { temperature change and } \\
\text { fuzzy linguistics }\end{array}$ & $\begin{array}{c}\text { Crisp Values of } \\
\text { Precipitation change and } \\
\text { fuzzy linguistics }\end{array}$ \\
\hline Am-Italy & $2020-2039$ & $+0.1(+)$ & $+41.22(+++)$ \\
Am-Portugal & $2020-2039$ & $-0.23(-)$ & $+12.98(+)$ \\
Am-Israel & $2080-2099$ & $+3.91(++)$ & $-28.09(--)$ \\
At-Israel & $2080-2099$ & $+3.91(++)$ & $-28.09(---)$ \\
Ec-Italy & $2020-2039$ & $+0.1(+)$ & $+41.22(+++)$ \\
Ec-Lebanon & $2020-2039$ & $+3.44(++)$ & $-15.51(--)$ \\
Ec-Portugal & $2020-2039$ & $-0.23(-)$ & $+12.98(+)$ \\
Ec-Cyprus & $2040-2059$ & $+4.29(++)$ & $+15.52(++)$ \\
Ec-Israel & $2080-2099$ & $+3.91(++)$ & $-28.09(---)$ \\
Tse-Italy & $2020-2039$ & $+0.1(+)$ & $+41.22(+++)$ \\
Tse-Israel & $2080-2099$ & $+3.91(++)$ & $-28.09(--)$ \\
Tg-Italy & $2020-2039$ & $+0.1(+)$ & $+41.22(+++)$ \\
Tg-Lebanon & $2020-2039$ & $+3.44(++)$ & $-15.51(-)$ \\
Tg-Portugal & $2020-2039$ & $-0.23(-)$ & $+12.98(+)$ \\
Tg-Cyprus & $2040-2059$ & $+4.29(++)$ & $+15.52(++)$ \\
\hline Acacia mearnsii=Am, Acridotheres & tristis $=$ At, Eupatorium & cannabinum=Ec, \\
Trachemys scripta elegans= Tse, Trogoderma granarium= Tg & \\
\hline
\end{tabular}


Table 8. Countries where invasive species have been recorded 1996-2015

\begin{tabular}{|c|c|c|c|c|c|c|c|c|c|c|c|}
\hline Species & & & $\mathrm{Cou}$ & tries & & & & & & & \\
\hline Acacia mearnsii & I & Is & $\mathrm{P}$ & $\mathrm{Sp}$ & & & & & & & \\
\hline Acridotheres tristis & & Is & & $\mathrm{Sp}$ & $\mathrm{T}$ & & & & & & \\
\hline Eupatorium & I & Is & $\mathrm{P}$ & $\mathrm{Sp}$ & $\mathrm{T}$ & A & $\mathrm{B}$ & $\mathrm{C}$ & $\mathrm{L}$ & S & \\
\hline cannabinum & I & Is & & $\mathrm{Sp}$ & & & & & & & \\
\hline $\begin{array}{c}\text { Trachemys scripta } \\
\text { elegans }\end{array}$ & I & & $\mathrm{P}$ & $\mathrm{Sp}$ & $\mathrm{T}$ & & B & $\mathrm{C}$ & $\mathrm{L}$ & S & $\mathrm{E}$ \\
\hline Trogoderma granarium & & & & & & & & & & & \\
\hline
\end{tabular}

The Acacia mearnsii has been recorded (for the period 1996-2015) in four Mediterranean countries (Italy, Portugal, Spain, Israel). The species Eupatorium cannabinum (Ec) and Trogoderma granarium $(\mathrm{Tg})$ are expected to appear in Greece from 2020-2039 because during these 20 years the Average Temperature and Precipitation (ATE_PR) in the country will become identical to the respective ones related to the time interval 1996-2015 in Lebanon, Italy and Portugal. The Eupatorium cannabinum (Ec) will increase the likelihood of appearance in Greece for the period 2080-2099, since at that time its ATE_PR will be similar to the ones of the 1996-2015 period, in 5 out of 10 countries (Tables 6 and 7). The Trogoderma granarium (Tg) will have an increased likelihood to migrate in Greece in the temporal zone 2040-2059. The Trachemys scripta elegans (Tse) will be migrating to Greece from 2080-2099 due to the very close similarity between Greece's ATEPR (during these 20 years) and the ones of Italy and Israel for the period (1996-2015).

Table 9. Related changes of the involved climate parameters as a result of the changes in the AVTE and AVPRE for the period 2080-2099

\begin{tabular}{ccc}
\hline $\begin{array}{c}\text { Climate } \\
\text { Parameters }\end{array}$ & $\begin{array}{c}\text { Fuzzification of temperature (+) } \\
\text { and Precipitation change }(+++)\end{array}$ & $\begin{array}{c}\text { Fuzzification of temperature } \\
(++) \text { and Precipitation change } \\
(---)\end{array}$ \\
\hline Aah & -0.02 & 0 \\
fd & 0.01 & 0 \\
pet & -0.02 & 0 \\
rh & 0.01 & 0 \\
sm & 0.08 & 0.01 \\
sf & -0.02 & 0 \\
wd & 0.01 & 0 \\
ws & -0.09 & 0.03 \\
wvp & -0.02 & 0 \\
wvsp & -0.02 & 0 \\
\hline
\end{tabular}

The combination of the small temperature increase $(+)$ with the high increase of precipitation $\mathrm{mm}(+++)$ results in the highest fluctuations for all interconnected parameters. On the other hand, the combination of Moderate average temperature increase (++) and the highest precipitation decrease in $\mathrm{mm}(---)$ causes mainly 
changes in the soil moisture. Overall, the highest positive relative change is observed in the soil moisture $(+0.08)$ which is mainly determined by the $\mathrm{mm}$ of precipitation $(+++)$.

\section{Conclusions and Future Work}

This paper proposes an innovative Soft Computing approach that estimates the temporal period in which five invasive species will be migrating to Greece. It is predicting the temporal period of their appearance based on the expected changes in average temperature and precipitation values in the country by 2100 due to climate change. Correlation Analysis has been performed with data from Greek repositories, related to twelve parameters for the period 1996-2015. The correlations have been fuzzified and the obtained Fuzzy Linguistics enabled the development of FCM. The model calculated the time-period during which the five most dangerous INS will expand in Greece. The projection of the AVPRE and AVTE of the country to the future, was based on sixteen well known and accepted climate models from today till 2100. In the near future we wish like to employ optimization methods like Genetic Algorithms and to combine them with heuristic approaches. Such hybrid modelling could enhance the dynamics of the system offering more effective and reliable results.

\section{References}

[1] Anezakis, V.D., Dermetzis, K., Iliadis, L., Spartalis, S.: Fuzzy cognitive maps for long-term prognosis of the evolution of atmospheric pollution based on climate change scenarios: the case of Athens. In: Nguyen, N.T., Iliadis, L., Manolopoulos, Y., Trawinski, B. (eds.) ICCCI 2016. LNCS, vol. 9875, pp. 175-186. Springer, Cham (2016). doi:10.1007/978-3-319-45243-2_16 [2] Anezakis, V.D., Demertzis, K., Iliadis, L., Spartalis, S.: Evolving Systems (2017). https://doi.org/10.1007/s12530-017-9196-6

[3] Asuero, A.G., Sayago, A., Gonzalez, A.G.: The Correlation Coefficient: An Overview, Critical Reviews in Analytical Chemistry, 36(1), 41-59 (2006).

https://doi.org/10.1080/10408340500526766

[4] Capinha, C., Anastácio, P., Tenedório, J.A.: Predicting the impact of climate change on the invasive decapods of the Iberian inland waters: An assessment of reliability. Biological Invasions 14(8), 1737-1751 (2012). doi: 10.1007/s10530-012-0187-z

[5] Coro, G., Vilas, L.G., Magliozzi, C., Ellenbroek, A., Scarponi, P., Pagano, P.: Forecasting the ongoing invasion of Lagocephalus sceleratus in the Mediterranean Sea. Ecological Modeling 371, 37-49 (2018). doi: 10.1016/j.ecolmodel.2018.01.007

[6] Gevrey, M., Worner, S.P.: Prediction of global distribution of insect pest species in relation to climate by using an ecological informatics method. Journal of Economic Entomology 99(3), 979-986 (2006).

[7] Gras, R., Devaurs, D., Wozniak, A., Aspinall, A.: An individual-based evolving predatorprey ecosystem simulation using a fuzzy cognitive map as the behavior model. Artificial Life 15(4), 423-463 (2009). doi: 10.1162/artl.2009.Gras.012

[8] Hoveka, L.N., Bezeng, B.S., Yessoufou, K., Boatwright, J.S., Van der Bank, M.: Effects of climate change on the future distributions of the top five freshwater invasive plants in South Africa. South African Journal of Botany 102, 33-38 (2016). doi: 10.1016/j.sajb.2015.07.017 
[9] Jung, J.M., Lee, W.H., Jung, S.: Insect distribution in response to climate change based on a model: Review of function and use of CLIMEX. Entomological Research 46(4), 223-235 (2016). doi: 10.1111/1748-5967.12171

[10] Jung, J.M., Jung, S., Ahmed, M.R., Cho, B.K., Lee, W.H.: Invasion risk of the yellow crazy ant (Anoplolepis gracilipes) under the Representative Concentration Pathways 8.5 climate change scenario in South Korea. Journal of Asia-Pacific Biodiversity 10(4), 548-554 (2017). doi: 10.1016/j.japb.2017.08.004

[11] Lowe, S., Browne, M., Boudjelas, S., De Poorter, M.: 100 of the World's Worst Invasive Alien Species: A selection from the Global Invasive Species Database. Published by The Invasive Species Specialist Group (ISSG) a specialist group of the Species Survival Commission (SSC) of the World Conservation Union (IUCN). Auckland, New Zealand (2000). [12] Paini, D.R., Worner, S.P., Cook, D.C., De Barro, P.J., Thomas, M.B.: Using a selforganizing map to predict invasive species: Sensitivity to data errors and a comparison with expert opinion. Journal of Applied Ecology 47(2), 290-298 (2010). doi: 10.1111/j.13652664.2010.01782.x

[13] Qin, Z., Zhang, J.E., DiTommaso, A., Wang, R.L., Liang, K.M.: Predicting the potential distribution of Lantana camara L. under RCP scenarios using ISI-MIP models. Climatic Change 134(1-2), 193-208 (2016). doi: 10.1007/s10584-015-1500-5

[14] Ramsey, D.S.L., Norbury, G.L.: Predicting the unexpected: Using a qualitative model of a New Zealand dryland ecosystem to anticipate pest management outcomes. Austral Ecology 34(4), 409-421 (2009). doi: 10.1111/j.1442-9993.2009.01942.x

[15] Robert, I.C., Hugh, J.M.: A neutral terminology to define 'invasive' species. Diversity and Distributions 10(2), 135-141 (2004). doi: 10.1111/j.1366-9516.2004.00061.x

[16] Sadeghi, R., Zarkami, R., Sabetraftar, K., Van Damme, P.: Use of support vector machines (SVMs) to predict distribution of an invasive water fern Azolla filiculoides (Lam.) in Anzali wetland, southern Caspian Sea, Iran. Ecological Modeling 244, 117-126 (2012). doi: 10.1016/j.ecolmodel.2012.06.029

[17] Salmeron, J.L., Froelich, W.: Dynamic Optimization of Fuzzy Cognitive Maps for Time Series Forecasting. Knowledge-Based Systems 105, 29-37 (2016).

doi: 10.1016/j.knosys.2016.04.023

[18] Scafetta, N., Willson, R.C.: ACRIM total solar irradiance satellite composite validation versus TSI proxy models. Astrophysics and Space Science 350(2), 421-442 (2014). doi:10.1007/s10509-013-1775-9

[19] Vidal, R., Salmeron, J.L., Mena, A., Chulvi, V.: Fuzzy cognitive map-based selection of TRIZ trends for eco-innovation of ceramic industry products. Journal of Cleaner Production 107, 202-214 (2015). doi: 10.1016/j.jclepro.2015.04.131

[20] Wang, C.J., Wan, J.Z., Zhang, Z.X.: Expansion potential of invasive tree plants in ecoregions under climate change scenarios: an assessment of 54 species at a global scale. Scandinavian Journal of Forest Research 32(8), 663-670 (2017).

doi: 10.1080/02827581.2017.1283049 